\title{
Special issue on the 11th meeting of the Society And Materials conference, SAM-11, NTNU, Trondheim, Norway, 15 and 16 May, 2017
}

\author{
Jean-Pierre Birat ${ }^{*}$ \\ IF Steelman, 5 chemin du Gâte-Chaux, 57280 Semécourt, France
}

Received: 29 May 2017 / Accepted: 7 February 2018

This special issue of Matériaux et Techniques publishes papers from the 11th meeting of the Society and Materials conference, $S A M-11$, which took place in Norway, at Trondheim's NTNU on 15 and 16 May, 2017.

This editorial is a summary of the meeting, highlighted by the peer-reviewed papers published in this special issue.

The conference program is shown in an appendix, while the presentations are available at http://www.sovamat. org/.

Five keynote lectures, 25 presentations and 10 posters were presented to an audience of 77 participants from 3 continents and 15 countries. The academia/RTO/industry distribution was $65-17-18 \%$, while the gender ratio was $43 / 57 \%$, males/females.

In the introductory, the pioneering and seminal role of NTNU in the fields of metals, society and societal metrics (MFA in particular) was emphasized.

Then, the chair of the scientific committee stressed the point that the conference was to bring together material "hard" sciences and social "soft" sciences. Moreover, the conference serves as an experimental laboratory, where new ideas are tested and discussed in terms of methodology but also of implementing them to solve strategic societal challenges: "if it is not new or disrupting, don't bring it to a SAM conference!! If it does not connect both material and social dimensions, do not propose it either!"

\section{The Circular Economy}

A long session on the Circular Economy opened the meeting.

The Circular Economy today is a political roadmap, which is part of the normative narratives about the various transitions that society is going through: energy transition, ecological transition, digital transition, food transition, etc.

\footnotetext{
* e-mail: jean-pierre.birat@ifsteelman.eu
}

However, the concept deserves critical examination, as it has been at the same time a long historical practice, which preceded the Linear Economy, and has become a current practice, where materials are usually doing well (i.e. exhibit high recycling rates), contrary to consumer goods and especially high-tech ones. Thus LCA, MFA and other tools can help provide the necessary critical depth to analyze the concept $^{1}$

In his keynote, Daniel Müller of NTNU, Norway provided his vision on the basis of the on-going MinFuture project $^{2}$ and of his extensive contributions to developing MFA as a strategic tool for analyzing the future. The key concept is to describe material cycles according to 4 dimensions:

- stages (primary and secondary raw materials);

- trade (globalization organizing the exchange of materials across the world);

- layers (materials are linked, not independent);

- time (historical and future studies).

The expected future outcome of MinFuture is to create an MFA database, which would eventually be available as an extension of a geographical tool like Google Maps. This would solve open needs of MFA, i.e. the availability of (public) data and the standardization of methodology. The metaphor of socioeconomic metabolism used by Müller is an interesting way of stressing the continuum between materials and society, the core theme of SAM conferences: collectively, we need more MFA work and effort!

Practical examples of glass recycling were given in the case of Quebec (Eco-Enterprises), emphasizing the political choices that have helped organize the collection (mass rather than qualitative collection). The collection of

\footnotetext{
${ }^{1}$ J.-P. Birat, Life-cycle assessment, resource efficiency and recycling, Metal. Res. Technol., 112 (2) (2015), 1, DOI: 10.1051/ metal $/ 2015009$.

${ }^{2}$ http://www.minfuture.eu/.
} 
good quality data in the case of the recycling of cars, as presented by IRT M2P of France, stressed the difficulty of generating data not available elsewhere in the datasphere and, thus, the challenge that producing high-level MFA studies faces. How best to carry out recycling, either in a centralized plant or locally, was discussed by MTB Recycling: which solution reduces costs while maximizing the sustainability of the solution? The answer is of course case by case, but the study emphasizes a service rather than a technology and thus enters into the realm of PSS (Product Service Systems), a concept discussed in several papers.

The Circular Economy does not only focus on materials but also on substances like Phosphorous (NTNU) or Potassium $^{3}$, which are used in fertilizers. There are limits to extending the concept much further though: the so-called "recycling of $\mathrm{CO}_{2}$ " does not belong to the Circular Economy because, in this case, energy is of the essence and it (exergy) is definitely non-conservative.

\section{New development in LCA methodology}

LCA is presently developing in several new directions.

Consequential LCA, which takes a broader, more societal view of the system under study, is becoming more common and ubiquitous.

LCA is often coupled with more complex and complementary models like in the work of CIRAIG, where a macroeconomic model is coupled with LCA in order to conduct foresight studies regarding new materials and new energy systems.

LCA is also used to assess the future of critical materials such as Lithium, bringing some conclusions but mostly identifying issues and uncertainties (Helmholtz Institute, Ulm).

The issue of allocations in $L C A$ was treated by 2 speakers. M. Pelote of IRT M2P, explained that end-oflife allocation can be implemented in different ways (End-of-Life, 50/50 or Recycled Content), depending on the political target of the work. G. Majeau-Bettez of CIRAIG addressed the issue of allocating the burden in systems that make several products and described a method for ensuring mass and energy balance in attributional LCA.

LCA ought to graduate into methods which are closer to physics and farther from accounting practices and therefore where physical conservation laws would always be respected: this would involve thinking in terms of thermodynamics, thermodynamical functions and getting closer to MFA by introducing sources and sinks (stocks), which somehow would represent the irreversibility of industrial and societal processes, and the corresponding increase of entropy.

And then, there are methodologies and approaches, which tackle the same kind of issues as LCA, but follow a different path. In this respect, S. Greene, of MIT, focused on how businesses report on their GHG emissions

\footnotetext{
$\overline{3}$ https://www.weforum.org/agenda/2015/11/africas-potashproblem/.
}

in their Sustainability or Corporate Social Responsibility (CSR) reports. The guiding light is provided by the Greenhouse Gas Protocol, which deals with the whole value chain, upstream and downstream of the firm's activities, and thus encompasses a wider system than LCA usually does, given all the derogations that it is usually awarded. Scope III emissions remain difficult to track, because of a lack of relevant data. This approach brings an original social dimension to GHG emission reporting.

\section{Social, societal \& economic}

F. MacKillop, of Heriot-Watt University, UK, gave a keynote on Society, Materiality and Resilience-Sustainability, thus analyzing some of the keywords that are tacked to the SAM conferences and fleshing them out conceptually, with a philosophical bent. His points are rooted in the work of Michel Callon, Bruno Latour and Ulrich Beck, who, all in their own way, stress that People, Mankind, Society, the Anthroposphere are connected to Nature, the Biosphere, in an organic and interactive way: this is called Constructivism Social Theory, Actor-Network Theory (ANT) and Theory of Risk. Nature does not simply dictate its laws to scientists as the interaction of anthroposphere and geosphere now deeply influences how society operates ${ }^{4}$ : anthropocentric arrogance is becoming passé, while the rule of experts is rejected, the concept and the role of the state are hollowing out and everyone has something to say about everything in spite of the growing complexity and chaos of the world. The recent radical political changes in the US and Europe are somehow related to this change of social paradigms. This, in turn, critically questions concepts like that of sustainability or of resilience, the property that nature was supposed to demonstrate in the face of human activities (aggressions?) but does not any longer. Cities, in particular, have a larger and larger role to play in the future at this continuously changing interface between Nature and Society (Ecourbanism).

A. Declich of the Laboratory of Citizenship Sciences, Italy, took the challenge a step further in his own keynote by examining the connection of society with materials and not simply with materiality. The sociology literature related to materials is scarce, because, in particular, "materials are invisible and obscure". A. Declich et al. have been exploring the subject since SAM-7 in Aix-la-Chapelle and contributing new directions of research on the subject at each edition of SAM. They introduced a number of useful concepts ${ }^{5}$ : social subjectivity related to materials/

\footnotetext{
${ }^{4}$ ANT is about "treating humans and non-humans "symmetrically": things and materials have agency, and humans are not in full control of material reality" (quote from MacKillop).

${ }^{5}$ L. d'Andrea, A. Declich, F. Feudo, Hidden societal implications of materials. Updating the awareness on what is at stake, Matériaux ES Techniques 102 (2014), 504.

L. d'Andrea, A. Declich, Materials, Technology and Society: contributions from a sociological perspective, Matériaux $\mathcal{E}$ Techniques 102 (2014), 507.
} 
technology, negotiation \& closure (the means by which scientists arrive at a consensus regarding a new development), social cycle of materials, anticipating uses and outcomes of technologies (materials are technologies), social dynamics of materials at work, in particular, in industrial symbiosis and urban regeneration, change \& innovation in materials made possible by the mobilization of social actors, strong connection with the energy transition and the various other transitions (ecological, digitization, circular economy, etc.), social fabric of innovation, activation of social energy. The new area of investigation, started this year, is related to gender issues, which are important due to the centrality of social actors in material development. The red thread is related to Design as the source of new technologies and new materials, and indeed "designers do have a gender" (Bratteteig). The under-representation of woman in research on materials thus causes the absence of a voice in the design process.

The social innovation paradigm was used as the guiding light in a study of man-robot interaction in a steelmaking practical situation (change of a ladle sliding gate) where cobots are used to assist a human operator (SSSA, Technische Universität Dortmund et al.). The point was to go beyond the simple development of a new technology, thus to look also at new working conditions, reorganization of work and eventually the co-creation of the new practice by process designers and operators-users.

\section{MFA}

Various original contributions to Material Flow Analysis (MFA) were presented in a special session, to which the keynote of the Circular Economy session should be added, discipline-wise.

Professor I. Daigo, of Tokyo University, gave an overview of steel accumulation, and of scrap hibernation and circulation in Japan and Asia. Hibernating stock is thus about $1 / 3$ of the total stock. The purity (contamination by tramp elements) of the scrap depends on the collection process, the care given to separating foreign materials from steel and also the maturity of the industrialization process. Thus, the long-term accumulation of impurities, which is not a serious problem today, may become more important in the future and thus ought to become a more active field of study.

JP. Birat, of IF Steelman, showed work carried out in Europe at Usinor in the 1990s (Cycle of Iron project) to develop an understanding of scrap accumulation and scrap recovery and which, in effect, led to the need for the full formal approach of LCA, thus accounting both for flows and stocks, at a time when the field was being constructed and conceptualized. There are several differences in the quality and granularity of the data available then, compared to what is available today.

F. Vasquèz, of NTNU, showed that MFA methodology can be applied to the diet of people to represent the evolution of body size and weight as a historical trend.

G. Liu, of University of Southern Denmark, presented a mapping of the spatial-temporal dynamics of global cement, steel, and aluminum in-use stocks.

\section{Industry and Industry of the Future}

Industry, which was less represented in this meeting than academia and research centers, made several important contributions on the theme of using sustainability tools to run their own research and their new product development effort.

Thus, ArcelorMittal, the steel producer, has developed an LCA tool for its own researchers to evaluate the sustainability of their own research projects and verify that they meet criteria derived from the company's sustainability targets. Additionally, it has a similar tool available to the users of steel in the construction sector, its largest market.

A car manufacturer, $P S A$, has also developed a tool for its design department to be used in the definition of new cars, which takes on board a full LCA of the future vehicle: it is a significant advance, as legislation, in Europe or North America, is still focusing on mileage and $\mathrm{CO}_{2}$ emissions, thus on the use phase of the vehicle, which amounts to neglecting the burden due to material production and endof-life and implementing "burden shifting", exactly what LCA has been designed to avoid.

In his keynote, L. Levacher of EDF, France presented the Smart Factory of the Future (SFoF), an element of the 4th Industrial Revolution - or the 3rd, depending on who is counting $^{6}$. SFoFs are:

- flexible;

- compatible with Industrie 4.0;

- eco-efficient;

- in harmony with human beings/society;

- behave as good citizens.

Important keywords like big data, additive manufacturing, product-service systems or PSS (products produce data), artificial intelligence (deep learning), cyber security, Blockchain's fully decentralized and distributed organization $^{7}$, etc., refer to one aspect or another of the SFoF. There is more and more evidence that the emerging factories of the future, those that are indeed creating more value, more jobs and are the most involved in innovation, will follow this model.

\section{Other sustainability metrics}

ESTEP, which speaks for the European Steel Sector, explained that biodiversity ought to be a criterion to evaluate the sustainability of steel (and other materials) and that biodiversity could also become a business development area for steel, for example, for building infrastructure related to biodiversity corridors.

In his keynote, L. Kolbensein of NTNU, Norway gave a crash course on process engineering, focusing on thermodynamics and on the value of using exergy rather than

\footnotetext{
${ }^{6}$ Jeremy Rifkin coined the expression 3rd Industrial revolution, while the European Commission prefers to speak about the 4 th. The Japanese government has been recently promoting Society 5.0 .

${ }^{7}$ The best-known example of a blockchain system is the bitcoin.
} 
energy to evaluate processes, and deflating some common misconceptions like that of the energy crisis ("the amount of raw materials is finite, but not that of energy as materials come from a closed system and energy from an open one"). He then went on to explain how the greening of the silicon industry, a large energy-intensive industry in Norway, can take place:

- make sure production does not include any fossil inputs;

- make sure process is suited for solar power - i.e. direct current and intermittent power;

- make sure there exists technologies (like CCS) to neutralize greenhouse gas emissions (e.g. $\mathrm{CO}_{2}$ and $\mathrm{CH}_{4}$ ); - work for a global ban on metals made from fossil fuels - or at least labeling of climate friendly metals (green principles formulated by Jorgen Randers).

TMR (Total Material Requirement), one of the indicators of Material Flow Accounting, has also been used as a new metrics for measuring the sustainability of automotive components (Ritsumeikan University, Japan). It emphasizes the total volumetric amount of resources collected from the environment to make a consumer good like an automobile: compared to the amount of material engaged in a car, the ratio is 20:1.

Management tools and metrics, derived from stakeholders' analysis, have been used to estimate the engagement of stakeholders in the Circular Economy (Federation of Indian Chambers of Commerce and Industry INDIA): namely, stakeholder engagement maturity model, 2-D and 3-D stakeholder maps, and stakeholder circle.

\section{Jean-Sébastien Thomas prize}

The Jean-Sébastien Thomas Prize, which is awarded to the best paper presented at the Conference, was attributed this year to F. MacKillop for his contribution on "Society, Materiality and Resilience-Sustainability".

\section{SAM-12}

The next meeting, SAM-12, is planned on 22-23 May, 2018, in Metz, France, information will be available in due time on http://www.sovamat.org/.

\section{Appendix: Program of the SAM-11 conference}

\section{Introductory - L. Kolbensein, NTNU, J.-P. Birat, IF Steelman, France}

\section{Session 1: Circular Economy-Chair: B. Laratte, Arts et Métiers, Bordeaux, France}

Keynote Lecture-Daniel Müller, NTNU, Norway-Circular Economy: Why? How? When?

In support of the circular economy: an exercise in stakeholder mapping, S. Bajaj, FICCI, India

The glass recycling industry: a concrete example of circular economy, M. Vermette, Eco Entreprises Québec, Canada
Recycling potential of secondary phosphorus resources as assessed by integrating substance flow analysis and plant availability, H. A. Hamilton, NTNU, Norway

To transport waste or transport recycling plant: insights from life-cycle analysis, G. Grimaud, MTB Recycling - Arts \& Métiers ParisTech, France

\section{Session 2: New Developments in LCA Methodology-Chair: Anne-Laure Hettinger, ArcelorMittal, Maizières-lès-Metz, France}

Keynote Lecture-Fionn MacKillop, Heriot-Watt University, Edinborough, UK - Society, materiality and resilience/ sustainability: global inquiries from the fields of industrial waste management, urban climate science and housing studies

Improving the modelling of avoided products in wastemanagement-oriented LCA, L. Rigamonti, Politecnico di Milano, Italy

Allocations and End-of-Life Management in LCA: How to decide?, M. Pelote, IRT M2P, France

Respecting material and energy balance in attributional LCA: reducing the influence of allocation, G. Majeau-Bettez, CIRAIG, Polytechnique Montréal, Canada

Assessing resource depletion impacts of lithium-ion batteries - What about the price?, J. F. Peters, Helmholtz Institute, Ulm, Germany

Combining LCA and prospective techno-economic models to assess the environmental and economic sustainability of emerging materials and energy pathways, A. Levasseur, CIRAIG, Polytechnique Montréal, Canada

Life Cycle Assessment of DurabRoads Materials, D. Deepankar, BSRIA Ltd, UK

\section{Session 3: Social and Economics-Chair: Valentina Colla, Scuola Superiore Sant'Anna, Pisa, Italy}

Integrated LCA \& LCC analysis to stimulate high quality recycling of construction \& demolition waste, A. Di Maria, KU Leuven, Belgium

What are we missing? Value chain greenhouse gas emissions accounting in the metals and minerals industry, S. Greene, MIT, USA

The impact of electric vehicles on lithium recycling - a critical analysis of material demand for a more sustainable mobility, S. Ziemann, Karlsruhe Institute of Technology, Germany

Keynote Lecture-Andrea Declich, LSC, Rome, Italy-Society and materials. An interpretation of the subject also in the light of gender

Taller, fatter, older and hungrier: a study of world population, human mass and caloric intake over the past 40 years, F. Vásquez, NTNU, Norway

Turning sustainability into a catalyst for innovation, A.-L. Hettinger, ArcelorMittal, France 
Introduction of symbiotic Human-Robot-Cooperation in the steel sector: an example of social innovation, V. Colla, Scuola Superiore Sant'Anna, TeCIP Institute, ICT-COISP Center, Italy

Local green economy indicators - case: rural villages in Lapland, K. Timonen, Natural Resources Institute Finland (Luke), Finland

\section{Session 4: MFA and other non-LCA} Methodologies-Chair: I. Daigo, University of Tokyo, Japan

Keynote Lecture-Laurent Levacher, EDF, Les Renardières, France-The smart factory of the future, revisited in 2017

Early attempts at developing an MFA for steel, J.-P. Birat, IF Steelman, France

Possibility of sustainable recycling of steel despite impurity contamination, I. Daigo, University of Tokyo, Japan

Mapping the spatial-temporal dynamics of global cement, steel, and aluminum in-use stocks, G. Liu, University of Southern Denmark, Denmark

Reconsideration of prioritization of automotive materials recycling in terms of total material requirement, E. Yamasue, Ritsumeikan University, Japan

Session 5: Sustainability and Eco-design of Processes, Products and Services-Chair: A. Levasseur, CIRAIG, Montreal, Canada

Keynote Lecture-Leiv Kolbeinsen, NTNU, Trondheim, Norway - The Importance of Silicon to Society

Steel and biodiversity: a promising alliance, K. Peters, ESTEP, Belgium, V. Colla, Scola Superiore Sant'Anna, Italy
Building ecodesign \& the role of steel in modern construction, R. Turconi, ArcelorMittal, France

Environmental assessment of innovations for car lightweighting, J. Garcia, Groupe PSA, France

Environmental assessment of PSS, feedback on 2 years of experimentation, R. Allais, PACTE CNRS UMR 5194, France

Materials and energy flow in the life cycle of leather: a case study of Bangladesh, C. Zia Uddin Md., Khulna University of Engineering \& Technology, Bangladesh

\section{SAM 10 Conclusions - J.-P. Birat, IF Steelman, France} Posters

Environmental performance of Li-ion batteries for direct marketing of wind power, M. Baumann, Karlsruhe Institute of Technology-Universidade Nova de Lisboa, Germany \& Portugal

Education of students and citizens for new materials, A. Delebarre, Mines ParisTech-PSL Research University Centre Thermodynamique des Procédés, France

Use of bio-based binder in the building sector, S. Gerbinet, University of Liège, Belgium

Ecodesign of a "vapour and air barrier membraneinsulator" system, following a cradle to cradle approachATISOLC2C, S. Groslambert, University of Liège, Belgium

LCA in space-Current status and future development, N. Ko, University of Stuttgart, Germany

Global distribution of material stocks: iron, copper, and nickel, K. Nakajima, National Institute for Environmental Studies, Japan

Environmental and Economic Sustainability Assessment of LED light bulb recycling in France, R. S. M. Mizanur, UTT, France

Cite this article as: Jean-Pierre Birat, Special issue on the 11th meeting of the Society And Materials conference, SAM-11, NTNU, Trondheim, Norway, 15 and 16 May, 2017, Matériaux \& Techniques 105, 501 (2017) 